\title{
Accelerometer-measured sedentary behaviour and physical activity of inpatients with severe mental illness
}

Citation for published version (APA):

Kruisdijk, F., Deenik, J., Tenback, D., Tak, E., Beekman, A-J., van Harten, P., Hopman-Rock, M., \& Hendriksen, I. (2017). Accelerometer-measured sedentary behaviour and physical activity of inpatients with severe mental illness. Psychiatry Research, 254, 67-74.

https://doi.org/10.1016/j.psychres.2017.04.035

Document status and date:

Published: 01/08/2017

DOI:

10.1016/j.psychres.2017.04.035

Document Version:

Publisher's PDF, also known as Version of record

Document license:

Taverne

Please check the document version of this publication:

- A submitted manuscript is the version of the article upon submission and before peer-review. There can be important differences between the submitted version and the official published version of record.

People interested in the research are advised to contact the author for the final version of the publication, or visit the DOI to the publisher's website.

- The final author version and the galley proof are versions of the publication after peer review.

- The final published version features the final layout of the paper including the volume, issue and page numbers.

Link to publication

\footnotetext{
General rights rights.

- You may freely distribute the URL identifying the publication in the public portal. please follow below link for the End User Agreement:

www.umlib.nl/taverne-license

Take down policy

If you believe that this document breaches copyright please contact us at:

repository@maastrichtuniversity.nl

providing details and we will investigate your claim.
}

Copyright and moral rights for the publications made accessible in the public portal are retained by the authors and/or other copyright owners and it is a condition of accessing publications that users recognise and abide by the legal requirements associated with these

- Users may download and print one copy of any publication from the public portal for the purpose of private study or research.

- You may not further distribute the material or use it for any profit-making activity or commercial gain

If the publication is distributed under the terms of Article $25 \mathrm{fa}$ of the Dutch Copyright Act, indicated by the "Taverne" license above, 


\title{
Accelerometer-measured sedentary behaviour and physical activity of inpatients with severe mental illness
}

\author{
Frank Kruisdijk ${ }^{\mathrm{a}, \mathrm{b}, *}$, Jeroen Deenik ${ }^{\mathrm{a}, \mathrm{c}}$, Diederik Tenback ${ }^{\mathrm{a}, \mathrm{d}}$, Erwin Tak ${ }^{\mathrm{b}, \mathrm{e}}$, Aart-Jan Beekman ${ }^{\mathrm{f}}$, \\ Peter van Harten ${ }^{\mathrm{a}, \mathrm{g}}$, Marijke Hopman-Rock ${ }^{\mathrm{b}, \mathrm{e}, \mathrm{h}}$, Ingrid Hendriksen ${ }^{\mathrm{b}, \mathrm{e}}$ \\ a GGz Centraal Innova, Amersfoort, The Netherlands \\ b Body@Work, TNO-VU University Medical Center, Amsterdam, The Netherlands \\ c University of Twente, Faculty of Behavioural, Management and Social sciences, Enschede, The Netherlands \\ d Utrecht University, Department of Pharmacoepidemiology and Clinical Pharmacology, Utrecht, The Netherlands \\ e The Netherlands Organisation for applied scientific research TNO, Leiden, The Netherlands \\ ${ }^{\mathrm{f}}$ VU University Medical Center, Department of Psychiatry, Amsterdam, The Netherlands \\ ${ }^{g}$ Maastricht University, School for Mental Health and Neuroscience, Maastricht, The Netherlands \\ h Department of Public and Occupational Health, EMGO institute for Health and Care Research, VU University Medical Center, Amsterdam, the Netherlands
}

\section{A R T I C L E I N F O}

\section{Keywords:}

Schizophrenia

Sedentary lifestyle

Accelerometry

Comorbidity

Inpatients

\begin{abstract}
A B S T R A C T
Sedentary behaviour and lack of physical activity threatens health. Research concerning these behaviours of inpatients with severe mental illness is limited but urgently needed to reveal prevalence and magnitude. In total, 184 inpatients (men $\mathrm{n}=108$, women $\mathrm{n}=76$, mean age 57,4, 20\% first generation antipsychotics, $40 \%$ second generation antipsychotics, 43\% antidepressants, mean years hospitalisation 13 years), with severe mental illness of a Dutch psychiatric hospital wore an accelerometer for five days to objectively measure total activity counts per hour and percentages in sedentary behaviour, light intensity physical activity and moderate to vigorous physical activity. Accelerometer data were compared with data of 54 healthy ward employees. Patients showed significantly less activity counts per hour compared to employees $(\mathrm{p}=0.02)$, although the differences were small $(d=0.32)$. Patients were sedentary during $84 \%$ of the wear time $(50 \mathrm{~min} / \mathrm{h})$, spend $10 \%$ in light intensity physical activity and $6 \%$ in moderate to vigorous physical activity. Age was the only significant predictor, predicting less total activity counts/h in higher ages. Decreasing sedentary behaviour and improving physical activity in this population should be a high priority in clinical practice.
\end{abstract}

\section{Introduction}

Recent epidemiological studies have shown that sedentary behaviour - defined as any waking behaviour in a sitting or reclining posture costing $\leq 1.5$ times the basal metabolic rate (Sedentary Behaviour Research Network, 2013) - is a major independent lifestyle risk factor for increased mortality and the development of cardiovascular disease, diabetes, obesity and cancer (Biswas et al., 2015; Brocklebank et al., 2015). Compared to the general population, patients with severe mental illness have an even higher risk of premature mortality and morbidity caused by cardiovascular disease and diabetes (Vancampfort et al., 2016): their life expectancy is 15-30 years lower and their risk of dying is 2.2 times higher. This mortality gap associated with mental illness has widened in recent decades (Walker et al., 2015). Risk factors for common health problems that underlie the abovementioned increased mortality are clustered in the metabolic syndrome, which is highly prevalent in this population (Vancampfort et al., 2015). In addition to management of weight and dietary habits, the level of physical activity is an important factor for reducing these risk factors (Stubbs et al., 2016a).

In the Netherlands, an estimated 107.000 patients have severe mental illness, of which 27.000 are permanent residents of a hospital or sheltered living environment (Goossens et al., 2010). The latter group, but probably even more patients, are likely at risk for the abovementioned health problems. To develop interventions that may improve health and reduce mortality, insight into the prevalence of sedentary behaviour and physical activity in patients with severe mental illness is essential (Firth et al., 2016).

More data on the prevalence of physical activity and sedentary behaviour, which is a distinctly different behaviour than physical inactivity (Sedentary Behaviour Research Network, 2013), is being acquired about patients with severe mental illness (Stubbs et al., 2016a,

\footnotetext{
* Correspondence to: GGz Centraal Hospitals, Department Innova, Amersfoort, The Netherlands.

E-mail address: f.kruisdijk@planet.nl (F. Kruisdijk).
} 
2016d). Until 2016, however, most research into sedentary behaviour and physical activity in this population included only outpatients, and the few published studies on inpatients included only patients with a relatively short stay, had a small number of participants, did not use a control group (except for one study), and generally used self-report questionnaires for sedentary behaviour and physical activity (Lindamer et al., 2008). These self-report questionnaires have shown limited reliability and tend to underestimate the amount of sedentary behaviour (Soundy et al., 2014) and overestimate physical activity (Dyrstad et al., 2014). In addition, co-morbid cognitive problems in patients with severe mental illness (Aleman et al., 1999) may cause an impairment of memory, influencing reproduction of their activities and thus limiting the self-reported registration of their behaviour.

To overcome the limitations of self-reporting, objective measurement of sedentary behaviour and physical activity by accelerometry offers valid and reliable registration and is now the preferred option (Soundy et al., 2014, 2015). In the current study, a majority of subjects were inpatients with severe mental illness, mainly schizophrenia, and we measured sedentary behaviour and physical activity objectively by means of accelerometry.

To date, little research has been performed in this population using accelerometry. Data on a comparable inpatient population, published by Chen (Chen et al., 2016) and Stubbs (Stubbs et al., 2016b), suggested that higher levels of sedentary behaviour and physical inactivity were independently associated with worse performance across several cognitive domains. Our current study, which included a more invalidated and hospitalized population than the abovementioned studies, may enhance the knowledge about activity and inactivity in the inpatient population and can lead to validation of measurement methods.

\section{Methods}

\subsection{Participants}

All subjects were inpatients on long-term psychiatric wards at a psychiatric hospital in the Netherlands. Patients were eligible if hospitalized for at least one year with a treatment history of at least two years. To ensure that the sample was representative of daily clinical practice, the following exclusion criteria were used: insufficient knowledge of Dutch language, a severe psychiatric or physical condition that prevented accelerometer measurement or being unable to provide informed consent. A comparison group of employees was formed, because comparing our patient data with published studies was difficult due to a lack of consensus about settings and data processing (KozeyKeadle et al., 2014). We included as many of the 80 available employees of the institution as possible. Exclusion criteria were: working nightshifts or insufficient knowledge of Dutch. The group was mixed in terms of gender, age and profession.

\subsection{Procedure}

Participants were asked to wear an accelerometer (ActiGraph GT3X + ) for five consecutive days (Wednesday morning to Sunday evening), except while sleeping or during water activities. Ward nurses were instructed on registration procedures, on managing the wearing time of the accelerometers and were asked to complete a short questionnaire about the physical inactivity level of each patient (inactivity-subscale of the NOSIE: Nurses' Observation Scale for Inpatient Evaluation) (Dingemans et al., 1984). Patients were instructed verbally per ward by JD ( $\mathrm{N} \approx 25$ wards of 10 patients each) and were told about the background of the research, the procedures and the measurement method. Their informed consent was requested, leaving patients free to refuse participation. Employees in the comparison group were instructed individually by JD and also received a written instructionguide. The comparison group was measured using the same procedures as the patient group. The Netherlands Central Committee on Research
Involving Human Subjects (CCMO) stated that no further ethical approval was necessary due to the minimal impact on patients of wearing an accelerometer for five days.

\subsection{Measurements}

Demographic variables (gender and age), Body Mass Index (BMI) and disease-characteristics (years of hospitalisation, diagnosis, illness severity and use of antipsychotics and antidepressants) were derived retrospectively from electronic patient records. Diagnoses were classified according to the DSM-IV-TR into three main groups: schizophrenia/other psychotic disorders, personality disorders and affective disorders. Incidental diagnoses were categorized as 'other disorders', such as substance-related diagnosis. Mood disorders were split into depression and bipolar, assuming more physical activity in (hypo) manic state. Antipsychotics were split into first generation, second generation or both. This is due to the differing effects these medications may have on physical activity: movement disorders are generally associated with first-generation antipsychotics, while metabolic side effects are associated with the second-generation (Owen et al., 2013).

Severity of illness was measured by the Dutch version of the severity scale from the Clinical Global Impression Scale (CGI, Nolen, 1990), consisting of one item (global severity of disease), rated by the psychiatrist from 1 (not at all ill) to 7 (extremely ill) (Busner and Targum, 2007). In the comparison group, only data on gender and age were collected. Sedentary behaviour and physical activity were measured by ActiGraph GT3X+ accelerometers (ActiGraph, Pensacola, Florida, VS) and analysed with ActiLife 6.8.0 software (same manufacturer). The accelerometers were worn on the right hip, and were held in place with an elastic strap between two belt loops or were placed in a small pouch that was pinned up on the same place. The ActiGraphs used firmware version 3.2.1, and accelerometer data were sampled at $100 \mathrm{~Hz}$ in order to obtain detailed data and prevent vigorous activity to be eliminated in data-processing, which may happen at lower sampling frequencies (Brond and Arvidsson, 2016). Data were downloaded at a user-specified time interval (epoch) of $1 \mathrm{~s}(1 \mathrm{~s})$ (Matthews et al., 2012). To avoid major data drop out, a wear time of more than six hours/day for at least three days was used as the criterion for a valid measurement. Periods with zero counts of $90 \mathrm{~min}$ or more, were defined as non-wear time (Choi et al., 2011).

We used the data of the Vector Magnitude variable, combining the data from all three axes, which appears to be more accurate than data from the vertical axis only (Santos-Lozano et al., 2013). Due to the previously mentioned lack of consensus about settings and dataprocessing in accelerometry measurement, we decided to use total activity counts per day, which had been suggested as a complementary outcome and potential standard for better comparability (Bassett et al., 2015). Patients' irregular daily rhythm and expected variance in wear time complicated the definition of a 'day'. Therefore, total activity counts/hour were calculated and percentage of valid wear time in sedentary behaviour $(<150$ counts $/ \mathrm{min})$, light intensity physical activity (151-3207 counts/min) and moderate to vigorous physical activity ( $\geq 3208$ counts $/ \mathrm{min}$ ) were reported (Santos-Lozano et al., 2013). For patients older than 65 years, the cut-off point for moderate to vigorous physical activity was fixed at $\geq 2751$ counts $/ \mathrm{min}$. Total activity counts/hour was used in the statistical analysis as continuous variable representing total activity. To compare patients' data, the same timeframe was used for each dataset: 09.00 a.m. till 10.00 p.m. Data from the comparison group was processed with the same settings and criteria. The GT3X + has a high inter- and intra-instrumental reliability and validity (McMinn et al., 2013; Gatti et al., 2016; Jarrett et al., 2015). The inactivity-subscale of the Nurse Observation Scale for Inpatient Evaluation, Dutch version (NOSIE; Dingemans et al., 1984) reflects the nurse's opinion about the level of physical inactivity of each patient, scoring inactivity behaviours and motor retardation in four items, on a scale from 0 (never) to 4 (always). The summed score of the 
four items is the main variable, with a range from 0 (no inactivity) to 16 (severe). The NOSIE shows a good inter-rater reliability (Hafkenscheid, 1991) and a Cronbach's alpha of 0.64 in the present study.

\subsection{Data analysis}

All statistical tests were conducted using SPSS version 21.0 (IBM SPSS Inc, 2012) and interpreted at 0.05 two-tailed significance level, unless noted otherwise. Continuous variables were examined for normality and homogeneity by comparing means with medians and standard deviations and by analysing frequency histograms and normality plots. If the assumption of normal distribution was violated, data was bootstrapped using 1000 samples with 95\% confidence intervals, bias-corrected and accelerated (Wright et al., 2011). Descriptive analyses were performed on each of the study variables. To check for differences between groups (participants/dropouts, attachment of accelerometers, men/women and patients/comparisons), independent $t$-tests and chi-square tests were conducted on continuous and categorical variables. For further analysis with categorical variables (diagnosis and medication), dummy variables were used. Therefore, the variables 'other diagnosis' and 'both generations antipsychotics' were the reference groups for diagnoses and medication types, respectively. Analysis of covariance (ANCOVA) was conducted to control for gender and age between patients and comparisons. Pearson correlations were calculated to assess bivariate associations between sedentary behaviour, physical activity and demographic and disease characteristics, and between sedentary behaviour, physical activity and the nurse-rated inactivity scores (0.05 two-tailed significance level). Hierarchical regression analyses (method Enter) were used to assess the degree to which demographic and disease characteristics could explain the variance in total activity counts/hour. In order to control for the method of attachment of the accelerometers, this was entered in the model first.

Demographic and disease characteristics were added into the second model. In the regression analysis, homogeneity and linearity were examined by scatterplots. Multicollinearity was examined by correlation coefficients and collinearity statistics (tolerance and VIF values).

\section{Results}

\subsection{Sample}

A total of 251 patients were eligible for the study, of which 16 were excluded because they were unable to give informed consent due to severe psychosis. Of the remaining 235 patients, 26 patients were not included for various reasons: refusal to sign informed consent $(n=24)$, removal $(n=1)$, bedridden patient $(n=1)$. This left 209 patients who were accelerometer registered. Of this group 23 were excluded from analysis due to incomplete data $(n=4)$ and inadequate wearing time $(n=19)$. The 184 remaining patients (response rate $=73 \%)$ were included in the analysis. This group had a higher proportion of men (59\%) compared to the group that was excluded from the analysis (43\%), $X^{2}(1, N=251)=4.71, p=0.03$. The participant group and the excluded group did not differ in terms of age, diagnosis, years of hospitalisation, disease-severity, BMI and medication. Of all available employees $(n=80), 26$ were excluded because they had to work nightshifts. The remaining 54 employees were all measured during a three-week-period; all of them complied with the required wearing time.

\subsection{Participant characteristics}

Table 1 shows the patient characteristics. Men were between 25 and 89 years old and women between 28 and 91 . Men were hospitalized for a minimum of one year and a maximum of 58 years, which was substantially longer than the female patients (1-41 years). The comparison group $(n=54)$ consisted of 16 men and 38 women. Men were between 23 and 61 years old and women between 38 and 63 years, with significantly fewer men in the comparison group (30\%), than in the patient group (59\%), $X^{2}(1, N=238)=14.13, p<0.001$ and with significantly younger age than the patient group, $t(236)=6.45$, $p<0.001$. We controlled for age and sex in further analysis.

\subsection{Sedentary behaviour and physical activity}

As shown in Table 2, the patient group had significantly fewer total activity counts/h than the comparison group. Although the accelerometers were more frequently attached to patients using a pouch, $X^{2}(1$,

Table 1

Demographics, disease characteristics and BMI of all patients, and for men and women separately.

\begin{tabular}{|c|c|c|c|c|c|c|c|}
\hline \multirow{2}{*}{$\begin{array}{l}\text { Variable (scale) } \\
\text { Age in years }\end{array}$} & \multicolumn{2}{|c|}{ Total $(\mathrm{n}=184)$} & \multicolumn{2}{|c|}{ Men $(n=108)$} & \multicolumn{2}{|c|}{ Women $(\mathrm{n}=76)$} & \multirow{2}{*}{$\begin{array}{l}p \\
0.20\end{array}$} \\
\hline & 57.4 & (12.8) & 56.5 & (12.1) & 58.9 & $(13.6)$ & \\
\hline Diagnosis, $n(\%)$ & & & & & & & 0.72 \\
\hline Schizophrenia and otherwise psychotic & 142 & $(77.2)$ & 82 & $(75.9)$ & 60 & $(78.9)$ & \\
\hline Personality disorder & 17 & $(9.2)$ & 12 & $(11.1)$ & 5 & $(6.6)$ & \\
\hline \multicolumn{8}{|l|}{ Mood disorder } \\
\hline Depressive & 6 & $(3.3)$ & 3 & $(2.8)$ & 3 & $(3.9)$ & \\
\hline Bipolar & 7 & $(3.8)$ & 5 & $(4.6)$ & 2 & $(2.6)$ & \\
\hline Others $^{\mathrm{a}}$ & 12 & $(6.5)$ & 6 & $(5.6)$ & 6 & $(7.9)$ & \\
\hline Years of hospitalisation ${ }^{\mathrm{b}}$ & 13.0 & (12.3) & 14.8 & $(13.2)$ & 10.7 & $(10.7)$ & 0.02 \\
\hline Severity of illness (scale $1-6)^{c}$ & 4.67 & $(1.36)$ & 4.51 & (1.39) & 4.89 & $(1.26)$ & 0.06 \\
\hline Body Mass Index (BMI) & 27.8 & $(6.2)$ & 27.7 & $(5.4)$ & 28.8 & $(7.0)$ & 0.05 \\
\hline \multicolumn{8}{|l|}{ Medication, $n(\%)$} \\
\hline Antipsychotics & & & & & & & 0.55 \\
\hline First generation & 36 & (19.6) & 21 & $(19.4)$ & 15 & $(19.7)$ & \\
\hline Second generation & 70 & $(38.0)$ & 45 & (41.7) & 25 & $(32.9)$ & \\
\hline Both & 73 & (39.7) & 40 & $(37.0)$ & 33 & $(43.4)$ & \\
\hline Antidepressants & 82 & $(44.6)$ & 46 & $(42.6)$ & 36 & $(47.4)$ & 0.52 \\
\hline
\end{tabular}

Mean (SD) unless otherwise noted.

Note. significant $\mathrm{p}$-values $(\mathrm{p}<0.05)$ are bold.

a Substance-related disorders $(\mathrm{n}=3)$; delirium, dementia, and amnestic and other cognitive disorders $(\mathrm{n}=3$ ); somatoform disorders $(\mathrm{n}=2)$; mental disorder not otherwise specified (n

$=2)$; anxiety disorder $(\mathrm{n}=1)$ and developmental disorder $(\mathrm{n}=1)$.

${ }^{\mathrm{b}}$ Skewed distribution, bootstrapped (1000 samples, 95\% confidence intervals BCa).

${ }^{\mathrm{c}}$ Higher scores mean higher severity of illness. 
Table 2

Objectively measured sedentary behaviour and physical activity compared between patients and comparisons.

\begin{tabular}{|c|c|c|c|c|c|}
\hline \multirow{2}{*}{$\begin{array}{l}\text { Variable (scale) } \\
\text { Wear time during measurement (hours) }{ }^{\mathrm{a}}\end{array}$} & \multicolumn{2}{|c|}{ Patients ( $\mathrm{n}=184$ ) } & \multicolumn{2}{|c|}{ Comparisons $(\mathrm{n}=54)$} & \multirow{2}{*}{$\begin{array}{l}p \\
0.004\end{array}$} \\
\hline & 54.6 & $(9.6)$ & 58.3 & $(7.80)$ & \\
\hline Total activity counts per hour ${ }^{\mathrm{a}}$ & 24527 & $(14822)$ & 35564 & (10778) & 0.001 \\
\hline \multicolumn{6}{|l|}{ Intensity during wear time } \\
\hline Sedentary behaviour (\%) & 83.6 & $(8.0)$ & 76.0 & $(4.6)$ & $<0.001$ \\
\hline Light physical activity (\%) & 10.5 & $(6.0)$ & 15.3 & $(3.0)$ & 0.001 \\
\hline Moderate to vigorous physical activity $(\%)^{\mathrm{a}}$ & 5.9 & $(4.3)$ & 8.8 & $(3.0)$ & 0.001 \\
\hline
\end{tabular}

Mean (SD).

Note. significant $\mathrm{p}$-values $(\mathrm{p}<0.05)$ are bold.

${ }^{a}$ Skewed distribution, bootstrapped (1000 samples, 95\% confidence intervals BCa).

$N=238)=11.93, p=0.001$ ), after controlling for the known differences in sex, age and attachment method, the difference in total activity counts/h remained highly significant, $F(1, N=238)=5.82, p=0.02$. However, the absolute differences were small $(d=0.32)$. Patients were predominantly sedentary. Although the comparison group scored about 1.5 times higher in light physical activity and moderate-to-vigorous physical activity than the patients, the comparison group also showed a high percentage of sedentary behaviour.

We initially found a sex difference in patients for both total activity counts/h and moderate-to-vigorous physical activity, with women showing lower values than men (Table 3). However, after controlling for wearing method (women wore a pouch more frequently than men $\left(X^{2}(1, N=184)=22.21, p<0.001\right)$ and the fact that patients who wore a pouch $(40 \%)$ scored significantly lower in total activity counts/ $\mathrm{h},(t(182)=2.96$ (bootstrapped CI $=2170.95-10265.25), p=0.003)$,

Table 3

Sedentary behaviour and physical activity scores of patients and comparisons for men and women.

\begin{tabular}{|c|c|c|c|c|c|}
\hline Variable (scale) & Men & & Women & & $p$ \\
\hline & \multicolumn{5}{|c|}{ Patients } \\
\hline $\mathrm{N}$ & 108 & & 76 & & \\
\hline $\begin{array}{l}\text { Subjectively rated inactivity } \\
\qquad(0-16)^{\mathrm{a}}\end{array}$ & 4.53 & $(2.75)$ & 4.78 & $(3.18)$ & 0.57 \\
\hline \multicolumn{6}{|l|}{$\begin{array}{l}\text { Objectively measured sedentary } \\
\text { behaviour and physical } \\
\text { activity }\end{array}$} \\
\hline $\begin{array}{l}\text { Wear time during measurement } \\
\quad{\text { (hours })^{\mathrm{b}}}^{\text {a }}\end{array}$ & 56.2 & $(7.8)$ & 52.3 & $(11.3)$ & 0.02 \\
\hline Total activity counts per hour ${ }^{\mathrm{b}}$ & 26,377 & $(16,597)$ & 21899 & $(11,451)$ & $0.04^{c}$ \\
\hline \multicolumn{6}{|l|}{ Intensity during wear time } \\
\hline Sedentary behaviour (\%) & 82.9 & $(8.3)$ & 84.7 & $(7.5)$ & 0.15 \\
\hline Light physical activity (\%) & 10.5 & $(6.0)$ & 10.5 & $(6.0)$ & 0.97 \\
\hline $\begin{array}{l}\text { Moderate to vigorous physical } \\
\text { activity }(\%)^{\mathrm{b}}\end{array}$ & 6.6 & $(4.9)$ & 4.9 & (3.1) & $0.01^{\mathrm{c}}$ \\
\hline \multicolumn{6}{|l|}{ Comparison group } \\
\hline $\mathrm{N}$ & 16 & & 38 & & \\
\hline \multicolumn{6}{|l|}{$\begin{array}{l}\text { Objectively measured sedentary } \\
\text { behaviour and physical } \\
\text { activity }\end{array}$} \\
\hline $\begin{array}{l}\text { Wear time during measurement } \\
\quad{\text { (hours })^{\mathrm{b}}}^{\text {a }}\end{array}$ & 60.34 & $(4.63)$ & 57.49 & $(8.71)$ & 0.12 \\
\hline Total activity counts per hour ${ }^{\mathrm{b}}$ & 34,234 & (9082) & 36,124 & $(11,483)$ & 0.50 \\
\hline \multicolumn{6}{|l|}{ Intensity during wear time } \\
\hline Sedentary behaviour (\%) & 76.2 & $(4.9)$ & 75.9 & $(4.6)$ & 0.83 \\
\hline Light physical activity (\%) & 15.6 & (3.4) & 15.9 & (2.9) & 0.55 \\
\hline $\begin{array}{l}\text { Moderate to vigorous physical } \\
\text { activity }(\%)^{\mathrm{b}}\end{array}$ & 8.2 & $(2.2)$ & 9.0 & (3.3) & 0.29 \\
\hline
\end{tabular}

Mean (SD)

Note. significant $\mathrm{p}$-values $(\mathrm{p}<0.05)$ are bold.

${ }^{\text {a }}$ Higher scores $=$ more inactivity.

${ }^{\text {b }}$ Skewed distribution, bootstrapped (1000 samples, 95\% confidence intervals BCa).

c After analysis of covariance with the way of attachment, men were no longer more active than women. no sex difference was found in total activity counts/h $(F(1, N=184)$ $=1.21, p=0.27)$ and moderate-to-vigorous physical activity $(F(1, N$ $=184)=3.41, p=0.07)$.

Because comparing accelerometer data between studies is difficult, for comparison purposes we used data from several recent studies with similar methods in populations of elderly people: the same accelerometer, length of time sampling interval (epoch) and wear-time validation settings. We recalculated our data using the same cut-off points as these studies, based on vertical axis counts (Table 4). Even compared to these data from mobility-limited older adults (without a current diagnosis of schizophrenia or other psychotic disorder) (Fitzgerald et al., 2015) and elderly people with mild-to-moderate Parkinson disease (Benka Wallen et al., 2015), our patients were much more sedentary, although they spent more time in moderate-tovigorous physical activity.

\subsection{Associations with background characteristics}

Pearson correlations showed significant associations between se-

Table 4

Comparison of ActiGraph GT3X(+) vertical axis data of the present study with two other studies, based on $1 \mathrm{~s}$ epochs and using wear time validation of Choi et al. (2011).

\begin{tabular}{|c|c|c|}
\hline Variable & Fitzgerald et al. (2015) & Benka Wallen et al. (2015) \\
\hline Population & $\begin{array}{l}\text { Mobility-limited older } \\
\text { adults }\end{array}$ & $\begin{array}{l}\text { Elderly people with mild to } \\
\text { moderate Parkinson disease }\end{array}$ \\
\hline $\mathrm{N}$ & 1170 & 79 \\
\hline$\%$ women & 66 & 47 \\
\hline Age, mean (SD) & $(5.3)$ & $(5.7)$ \\
\hline \multicolumn{3}{|l|}{$\begin{array}{l}\text { Used cut-off points } \\
\quad \text { (counts per minute) }\end{array}$} \\
\hline Sedentary behaviour & $0-99$ & 0-99 \\
\hline Light physical activity & $100-499$ & $100-759$ \\
\hline $\begin{array}{c}\text { Moderate to vigorous } \\
\text { physical activity }\end{array}$ & $>500$ & $\geq 760$ \\
\hline \multicolumn{3}{|l|}{$\%$ of time in } \\
\hline Sedentary behaviour & 77.0 & 75.9 \\
\hline Light physical activity & 16.6 & 18.1 \\
\hline $\begin{array}{c}\text { Moderate to vigorous } \\
\text { physical activity }\end{array}$ & 6.4 & 6.0 \\
\hline \multicolumn{3}{|l|}{$\begin{array}{l}\text { Recalculated outcomes } \\
\text { present study }\end{array}$} \\
\hline \multicolumn{3}{|l|}{ Patients, $\%$ of time in } \\
\hline Sedentary behaviour & 88.4 & 88.4 \\
\hline Light physical activity & 2.4 & 3.4 \\
\hline $\begin{array}{c}\text { Moderate to vigorous } \\
\text { physical activity }\end{array}$ & 9.2 & 8.2 \\
\hline \multicolumn{3}{|l|}{$\begin{array}{l}\text { Comparison group, } \% \text { of } \\
\text { time in }\end{array}$} \\
\hline Sedentary behaviour & 84.3 & 84.3 \\
\hline Light physical activity & 3.4 & 4.9 \\
\hline $\begin{array}{c}\text { Moderate to vigorous } \\
\text { physical activity }\end{array}$ & 12.3 & 10.8 \\
\hline
\end{tabular}


Table 5

Hierarchical regression for the total activity counts per hour (bias-corrected and accelerated bootstrap, 1000 samples; $\mathrm{N}=184$ ).

\begin{tabular}{|c|c|c|c|c|c|c|c|c|}
\hline \multirow[b]{2}{*}{ Variable } & \multicolumn{4}{|l|}{ Model 1} & \multicolumn{4}{|l|}{ Model 2} \\
\hline & $B$ & $S E B$ & $\begin{array}{l}95 \% \text { CI } \\
\text { Min }\end{array}$ & Max & $B$ & $S E B$ & $\begin{array}{l}95 \% \text { CI } \\
\text { Min }\end{array}$ & Max \\
\hline $\begin{array}{l}\text { Way of attachment }{ }^{\mathrm{a}} \\
\text { Gender } \\
\text { Age }\end{array}$ & $-6464.55^{k \star x}$ & 2167.77 & -10487.83 & -2213.72 & $\begin{array}{l}-2995.26 \\
-1382.26 \\
-\mathbf{5 3 1 . 2 4}\end{array}$ & $\begin{array}{l}1982.90 \\
1961.87 \\
95.67\end{array}$ & $\begin{array}{l}-6738.30 \\
-5242.74 \\
-718.73\end{array}$ & $\begin{array}{l}1060.34 \\
2256.41 \\
-346.54\end{array}$ \\
\hline \multicolumn{9}{|l|}{ Diagnosis $^{c}$} \\
\hline Schizophrenia & & & & & 4223.27 & 2508.24 & -341.26 & 9043.94 \\
\hline Personality disorder & & & & & -7.83 & 2738.48 & -5154.41 & 5306.02 \\
\hline Depressive disorder & & & & & 1746.34 & 6109.31 & -9347.07 & 13279.47 \\
\hline Bipolar disorder & & & & & 5319.01 & 5720.52 & -4635.89 & 15853.59 \\
\hline Years of hospitalisation & & & & & 12.09 & 78.85 & -132.52 & 148.64 \\
\hline Severity of illness & & & & & -1165.54 & 818.13 & -2742.86 & 563.31 \\
\hline Body Mass Index & & & & & -85.16 & 144.60 & -385.67 & 182.60 \\
\hline \multicolumn{9}{|l|}{ Antipsychotics $^{\mathrm{d}}$} \\
\hline First generation & & & & & -2984.31 & 2027.87 & -6842.74 & 1250.14 \\
\hline Second generation & & & & & -1289.85 & 1992.05 & -4990.78 & 2566.89 \\
\hline Antidepressants & & & & & 717.59 & 1945.29 & -2935.69 & 4290.83 \\
\hline$R^{2}$ & 0.05 & & & & 0.33 & & & \\
\hline$R_{A d j}^{2}$ & 0.04 & & & & 0.28 & & & \\
\hline$F$ & $8.77^{*}$ & & & & $6.33^{* * *}$ & & & \\
\hline
\end{tabular}

Note. significant coefficients are bold.

${ }^{\text {a }}$ strap between belt loops $=0$, pouch $=1$.

${ }^{\mathrm{b}}$ men $=0$, women $=1$.

c reference group: 'other diagnosis'.

d reference group: 'both generation antipsychotics'.

$* p<0.01$.

$* * p \leq 0.001$

dentary behaviour, physical activity and background characteristics. Younger age was moderately associated with less sedentary behaviour ( $r=0.38, p<0.001)$, and more moderate-to-vigorous physical activity $(r=-0.51, p<0.001)$ and total activity counts/h $(r=-0.53$, $p<0.001$ ). Years of hospitalisation, a diagnosis of schizophrenia, personality disorder and 'other' showed weaker associations with various sedentary behaviour and physical activity variables, reflected in associations with total activity counts/h $(r=-0.16, p<0.05 ; r$ $=0.27, p<0.001 ; r=-0.18, p<0.05 ; r=-0.22, p<0.01$, respectively). However, all these variables were also significantly associated with age; after performing the hierarchical regression, age remained the only significant predictor (Table 5). The model also showed that, after controlling for these patient characteristics, the wearing method was not a significant predictor of the measured total activity counts/h. The resulting total model was significant, with a substantial explained variance. Finally, lower nurse-rated inactivity scores showed mediumto-strong correlations with lower total activity counts/h $(r=-0.35$, $p<0.001)$, more sedentary behaviour $(r=0.39, p<0.001)$, less light physical activity $(r=-0.31, p<0.001)$ and less moderate-to-vigorous physical activity $(r=-0.30, p<0.001)$.

\section{Discussion}

To our knowledge, this is one of the first studies measuring sedentary behaviour and physical activity using accelerometry in a large group of hospitalized patients with severe mental illness. These measurements showed significantly lower total activity counts per hour in patients than in the comparison group. Moreover, the patients were sedentary on average $84 \%$ of their awake time. These findings are in line with other studies in this population which used self-reports to measure physical activity (Ussher et al., 2007; Vancampfort et al., 2013; Stubbs et al., 2016d). However, only one accelerometer study with inpatients was included in the meta-analysis of Stubbs. That study (Snethen et al., 2014) was based on a relatively small group of 30 participants with schizophrenia, with an unknown proportion of them being outpatients in a day hospital programme. Razavi et al. (2011) also used actigraphy in a population with psychiatric inpatients suffering from major depression in a first or recurrent episode. They showed that actigraphy was more precise in reflecting the motor activity parameters of the Hamilton Depression Rating Scale than the score of experts. However, comparison with our study is limited due to the actigraph type, method of registration and wear-time. It is noteworthy that in our study not only participants with schizophrenia were included but also a minority with other diagnoses, for instance major depression, as a result of a broad definition of a patient with severe mental illness (Walker et al., 2015).

Consequently, our accelerometer study contributes to the field, not only due to our relatively large group of inpatient participants with severe mental illness, but also due to our relatively precise accelerometry measurements of sedentary behaviour and physical activity. As mentioned by Bassett et al. (2015), registration with an accelerometer gives a more reliable and detailed representation of the activity levels in a variety of domains and more accurate registration of sedentary behaviour and random physical activity in the lower spectrum of intensity. The recent accelerometer studies of Chen and Stubbs (Chen et al., 2016; Stubbs et al., 2016b) also showed that inpatients with schizophrenia in Taiwan spend significantly less time in light physical activity and moderate-to-vigorous physical activity than a comparison group without the disease. However, data from that study are difficult to compare with those from our study. Not only did they use wrist-worn and hip-worn accelerometers (Shiroma et al., 2016), but also a binary split into low ( $<581.1$ min per day) and high sedentary behaviour ( $>581.1$ min per day) instead of the three intensities sedentary, light physical activity and moderate-to-vigorous physical activity used in our study. Although the authors emphasized the importance of separating sedentary behaviour from light physical activity, no similar data on sedentary behaviour are available. Moreover, severity of illness has not been standardized internationally, which also results in poor comparability between patient samples. Finally, their patients were younger (mean age of 44 compared to 57.4 in our study), had a lower BMI (24.3 compared to 27.8), and had fewer years of hospitalisation (14.2 months compared to 13 years). However, the direction of the findings is 
comparable with our study. Their advice was also to engage patients in more light activity instead of sedentary behaviour. No guidelines are currently available for sedentary behaviour, but relative to other accelerometry data we can conclude that the percentage of sedentary time is very high in this population. Based on these findings, we suggest making it priority to reduce sedentary behaviour in this population in favour of light physical activity. The shift from sedentary behaviour to light physical activity implies a relatively moderate increase in activity. In clinical practice this can be accomplished by a broad multidisciplinary lifestyle intervention programme.

Several of our outcomes were unexpected. First, we found an association only between sedentary behaviour and age, and no association with antipsychotic medication regarding the sedative and metabolic side-effects of this medication. Chen et al. (2016), Stubbs et al. (2016b) also found no association between physical activity and chlorpromazine equivalents. Future intervention studies that aim to decrease sedentary behaviour could look for possible associations with changes in clinical variables. In particular, further study of the effect of psychotropic medication on sedentary behaviour is necessary (Stubbs et al., 2016c).

A second unexpected outcome was that we found no differences in sedentary behaviour and physical activity between men and women. This differs from findings in previous studies with less severely mentally ill populations, such as outpatients in regular health care (Janney et al., 2008) and outpatients with severe mental illness (Daumit et al., 2005), but is in line with the findings of the above-mentioned studies of Chen et al. (2016), Stubbs et al. (2016b) in an inpatient population. It is possible that gender has less association with activity levels in patients who are hospitalized for a long time. However, because of the significant difference in gender between our participant group, the group excluded from the analysis and the comparison group (both included predominantly women), studies with more patients are necessary to make stronger statements about this finding.

A third unexpected outcome concerns sedentary behaviour of the comparison group of employees. Even the adjusted data based on the vertical axis showed that they spent more time in sedentary behaviour (84.3\%) than older adults with mobility issues (78.5\%) (Fitzgerald et al., 2015) and elderly patients with mild-to-moderate Parkinson disease (75.9\%) (Benka Wallen et al., 2015). These studies provided reliable data for comparison concerning the transparency in the settings of handling and processing accelerometer data. Nevertheless, the exclusion of hours with less than $54 \mathrm{~min}$ of data registration in the study of Benka Wallen et al. (2015) and our choice of using a sampling frequency of $100 \mathrm{~Hz}$ instead of $30 \mathrm{~Hz}$ in both comparison studies may have resulted in more sedentary behaviour counts in our study. Other possible differences in these studies (e.g. attachment methods, time standardisation, environment and culture) could also have caused bias. In addition, using only the vertical axis may not be the most suitable measurement to compare the activity intensities of these different groups. However, our data still strongly support the initiatives that involve staff in lifestyle interventions in mental health care.

Our study has several limitations concerning study design, methodological considerations, data comparison and disease characteristics of the population. First, the cross-sectional design offers valuable information about associations between the various parameters, but does not allow any interpretations about potential causal relationships.

Second, methodological and technical limitations are due to the lack of literature on accelerometer-based data in this specific inpatient population for physical activity and sedentary behaviour. As a result, no validated settings are available for collecting and processing the accelerometer data of these patients, such as sampling frequency, wear time, time intervals (epochs) and cut-points. Although we used a high sampling frequency of $100 \mathrm{~Hz}$ to obtain detailed data to prevent the loss of vigorous acceleration in data processing that occurs with lower frequencies (e.g. the default $30 \mathrm{~Hz}$ ), the high frequency can cause bias by additional activity counts that escaped the band-pass filter while processing data. Consequently, we may have overestimated the percentage of vigorous activity. This could mean that physical activity among our participants was even worse than reported.

Third, our minimum wear time for accelerometer data (six hours for at least three days) was less than the advised $10 \mathrm{~h}$ a day (Troiano et al., 2008). However, many patients have irregular circadian rhythms, resulting in fewer hours of valid wear time. Therefore, we followed the daily schedule on most wards to determine the minimum wear time per day and the specified timeframe (09:00 a.m.-10:00 p.m.), to be able to compare data between patients.

Concerning time intervals, 1-s epochs were chosen because longer time intervals result in a higher likelihood of misclassifying daily activity (Matthews et al., 2012). To determine wear time, we followed the guidelines of Choi et al. (2011), which stated that 1-second epochs result in the fewest misclassifications.

A fourth limitation consisted of the choice of cut-off points, because this differs according to the accelerometer model, firmware version, settings and the age of the subjects (due to differing energy expenditure) (Colley and Tremblay, 2011; Hooker et al., 2011; Trost et al., 2011; Freedson et al., 2012). Moreover, existing cut-off points are mostly based on uni-axial measurement, while recent research states that a combination of three axis (Vector Magnitude) produces more accurate results (Santos-Lozano et al., 2013). We used the cut-off points based on the vector magnitude values of an almost identical accelerometer (ActiGraph GT3X), and we made a distinction in cut-off points between adults and elderly people, which turned out to be the best way to define sedentary behaviour (Kozey-Keadle et al., 2011; Carr and Mahar, 2012).

As mentioned above, a variety of accelerometers and preferred settings are available for data collection and processing (e.g. sampling frequency, epoch length, use of uni-axial or tri-axial data, wear-time validation and cut-off points). However, standardisation and consensus is urgently needed to improve comparability because studies use different methods which are often poorly reported, making comparison difficult. By using total activity counts, which was recently suggested to reach a better standard for comparability between studies (Bassett et al., 2015), we took initial steps towards more comparable accelerometer data. Although we had to use total activity counts/h instead of total activity counts/day as a result of the limited wear time, studies in which it is possible to measure 'a day' can translate their total activity counts per day into hours to compare their results with ours. In addition, due to the severity of mental illness in this population, we had to develop new ways to attach the accelerometers in order to minimize discomfort. It is possible this might have caused not fully comparable data, because we did not validate these methods.

A final limitation concerns our decision to not use self-reporting in our study, which prevents comparability with accelerometry data. We did this because self-reports are not reliable measuring instruments in this population (Soundy, 2014) due to illness severity and cognitive deficits. Also, because the burden of wearing an accelerometer for this population was already high, we decided to use the nurse observation scale (NOSIE; Dingemans et al., 1984) instead.

\section{Conclusion}

This accelerometer study has shown that hospitalized patients with severe mental illness are very sedentary and physically inactive. In this population, registration of sedentary behaviour and physical activity with accelerometers is probably more accurate and reliable than selfreporting and is therefore preferable. In addition, this approach enables the standardisation of settings, which is required to provide future research in a comparable population with an accurate method to measure sedentary behaviour and physical activity. Standardized and longitudinal objective measurement of sedentary behaviour and physical activity in this patient group is needed to confirm the current prevalence data, combined with a suitable control group, to study 
potential causal relationships. Considering the well-known comorbidities in this population, resulting in greatly decreased life expectancy, reducing sedentary behaviour and improving physical activity should be a high priority.

\section{Funding}

None.

\section{Conflict of interest}

AJB received honorarium as a speaker from Lundbeck (no relation with this study). Other authors: no conflicts of interest.

\section{Acknowledgements}

The authors wish to thank the staff, nurses and patients for their efforts and participation in the study, and the University of Twente for participating in the study design.

\section{References}

Aleman, A., Hijman, R., De Haan, E.H.F., Kahn, R.S., 1999. Memory impairment in schizophrenia: a meta-analysis. Am. J. Psychiatry 156 (9), 1358-1366.

Bassett, D.R., Troiano, R.P., McClain, J.J., Wolff, D.L., 2015. Accelerometer-based physical activity: total volume per day and standardized measures. Med. Sci. Sports Exerc. 47 (4), 833-838.

Benka Wallen, M., Franzen, E., Nero, H., Hagstromer, M., 2015. Levels and patterns of physical activity and sedentary behavior in elderly people with mild to moderate Parkinson disease. Phys. Ther. 95 (8), 1135-1141.

Biswas, A., Oh, P.I., Faulkner, G.E., Bajaj, R.R., Silver, M.A., Mitchell, M.S., Alter, D.A., 2015. Sedentary time and its association with risk for disease incidence, mortality, and hospitalization in adults A systematic review and meta-analysis. Ann. Intern. Med. 162 (2), 123-132.

Brocklebank, L.A., Falconer, C.L., Page, A.S., Perry, R., Cooper, A.R., 2015. Accelerometer-measured sedentary time and cardiometabolic biomarkers: a systematic review. Prev. Med. 76, 92-102.

Brond, J.C., Arvidsson, D., 2016. Sampling frequency affects the processing of Actigraph raw acceleration data to activity counts. J. Appl. Physiol. 120 (3), 362-369.

Busner, J., Targum, S.D., 2007. The clinical global impressions scale: applying a research tool in clinical practice. Psychiatry (Edgmont) 4 (7), 28-37.

Carr, L.J., Mahar, M.T., 2012. Accuracy of intensity and inclinometer output of three activity monitors for identification of sedentary behavior and light-intensity activity. J. Obes. http://dx.doi.org/10.1155/2012/460271.

Chen, L.J., Steptoe, A., Chung, M.S., Ku, P.W., 2016. Association between actigraphyderived physical activity and cognitive performance in patients with schizophrenia. Psychol. Med. 46 (11), 2375-2384.

Choi, L., Liu, Z., Matthews, C.E., Buchowski, M.S., 2011. Validation of accelerometer wear and nonwear time classification algorithm. Med. Sci. Sports Exerc. 43 (2), 357-364.

Colley, R.C., Tremblay, M.S., 2011. Moderate and vigorous physical activity intensity cutpoints for the Actical accelerometer. J. Sports Sci. 29 (8), 783-789.

Daumit, G.L., Goldberg, R.W., Anthony, C., Dickerson, F., Brown, C.H., Kreyenbuhl, J., Wohlheiter, K., Dixon, L.B., 2005. Physical activity patterns in adults with severe mental illness. J. Nerv. Ment. Dis. 193 (10), 641-646.

Dingemans, P.M., Bleeker, J.A.C., Frohn-De Winter, M.L., 1984. A cross-cultural study of the reliability and factorial dimensions of the nurses' observation scale for inpatient evaluation (NOSIE). J. Clin. Psychol. 40 (1), 169-172.

Dyrstad, S.M., Hansen, B.H., Holme, I.M., Anderssen, S.A., 2014. Comparison of selfreported versus accelerometer-measured physical activity. Med. Sci. Sports Exerc. 46 (1), 99-106.

Firth, J., Rosenbaum, S., Stubbs, B., Gorczynski, P., Yung, A.R., Vancampfort, D., 2016. Motivating factors and barriers towards exercise in severe mental illness: a systematic review and meta-analysis. Psychol. Med. 46 (14), 2869-2881.

Fitzgerald, J.D., Johnson, L., Hire, D.G., Ambrosius, W.T., Anton, S.D., Dodson, J.A., Marsh, A.P., McDermott, M.M., Nocera, J.R., Tudor-Locke, C., White, D.K., Yank, V., Pahor, M., Manini, T.M., Buford, T.W., 2015. Association of objectively measured physical activity with cardiovascular risk in mobility-limited older adults. J. Am. Heart Assoc. 4 (2). http://dx.doi.org/10.1161/JAHA.114.001288.

Freedson, P.S., Bowles, H.R., Troiano, R., Haskell, W., 2012. Assessment of physical activity using wearable monitors: recommendations for monitor calibration and use in the field. Med. Sci. Sports Exerc. 44 (SUPPL. 1), S1-S4.

Gatti, A.A., Stratford, P.W., Brenneman, E.C., Maly, M.R., 2016. GT3X+ accelerometer placement affects the reliability of step-counts measured during running and pedalrevolution counts measured during bicycling. J. Sports Sci. 34 (12), 1168-1175.

Goossens, P.J.J., Wesselink, W., Janssen, W.F.A., 2010. Palliatieve zorg bij mensen met een psychiatrische stoornis. In: Wanrooij, B.S. (Ed.), Palliatieve Geneeskunde. Bohn Stafleu van Loghum, Houten, pp. 309.

Hafkenscheid, A., 1991. Psychometric evaluation of the Nurses Observation Scale for Inpatient Evaluation in the Netherlands. Acta Psychiatr. Scand. 83 (1), 46-52.
Hooker, S.P., Feeney, A., Hutto, B., Pfeiffer, K.A., McIver, K., Heil, D.P., Vena, J.E., LaMonte, M.J., Blair, S.N., 2011. Validation of the actical activity monitor in middleaged and older adults. J. Phys. Act. Health 8 (3), 372-381.

IBM SPSS Inc, 2012. Statistical Package for the Social Sciences (SPSS) 21.0 for Windows. IBM SPSS Incorporated, Chicago, IL.

Janney, C.A., Richardson, C.R., Holleman, R.G., Glasheen, C., Strath, S.J., Conroy, M.B., Kriska, A.M., 2008. Gender, mental health service use and objectively measured physical activity: data from the National Health and Nutrition Examination Survey (NHANES 2003-2004). Ment. Health Phys. Act. 1 (1), 9-16.

Jarrett, H., Fitzgerald, L., Routen, A.C., 2015. Interinstrument Reliability of the ActiGraph GT3X + Ambulatory Activity Monitor During Free-Living Conditions in Adults. J. Phys. Act. Health 12 (3), 382-387.

Kozey-Keadle, S., Shiroma, E.J., Freedson, P.S., Lee, I.M., 2014. Impact of accelerometer data processing decisions on the sample size, wear time and physical activity level of a large cohort study. BMC Public Health 14 (1), 1210.

Kozey-Keadle, S., Libertine, A., Lyden, K., Staudenmayer, J., Freedson, P., 2011. Validation of wearable monitors for assessing sedentary behavior. Med. Sci. Sports Exerc. 43 (8), 1561-1567.

Lindamer, L.A., McKibbin, C., Norman, G.J., Jordan, L., Harrison, K., Abeyesinhe, S., Patrick, K., 2008. Assessment of physical activity in middle-aged and older adults with schizophrenia. Schizophr. Res. 104 (1-3), 294-301.

Matthews, C.E., Hagströmer, M., Pober, D.M., Bowles, H.R., 2012. Best practices for using physical activity monitors in population-based research. Med. Sci. Sports Exerc. 44, S68-S76.

McMinn, D., Acharya, R., Rowe, D.A., Gray, S.R.A., Allan, J.L.A., 2013. Measuring activity energy expenditure: accuracy of the GT3X + and actiheart monitors. Int. J. Exerc. Sci. 3, 217-229.

Nolen, W.A., 1990. Globale Klinische Beoordeling (Clinical Global Impression: CGI) UMC, Groningen. 〈http://www.tijdschriftvoorpsychiatrie.nl/ measuringinstruments/29>.

Owen, R.R., Drummond, K.L., Viverito, K.M., Marchant, K., Pope, S.K., Smith, J.L., Landes, R.D., 2013. Monitoring and managing metabolic effects of antipsychotics: a cluster randomized trial of an intervention combining evidence-based quality improvement and external facilitation. Implement. Sci. 8, 120.

Razavi, N., Horn, H., Koschorke, P., Hugli, S., Hofle, O., Muller, T., Strik, W., Walther, S. 2011. Measuring motor activity in major depression: the association between the Hamilton Depression Rating Scale and actigraphy. Psychiatry Res. 190 (2-3), 212-216.

Santos-Lozano, A., Santin-Medeiros, F., Cardon, G., Torres-Luque, G., Bailon, R., Bergmeir, C., Ruiz, J.R., Lucia, A., Garatachea, N., 2013. Actigraph GT3X: validation and determination of physical activity intensity cut points. Int. J. Sports Med. 34 (11), 975-982.

Sedentary Behaviour Research Network, 2013. Standardized use of the terms "sedentary" and "sedentary behaviours". Ment. Health Phys. Act. 6 (1), 55-56.

Shiroma, E.J., Schepps, M.A., Harezlak, J., Chen, K.Y., Matthews, C.E., Koster, A., Caserotti, P., Glynn, N.W., Harris, T.B., 2016. Daily physical activity patterns from hip- and wrist-worn accelerometers. Physiol. Meas. 37 (10), 1852-1861.

Snethen, G.A., McCormick, B.P., Lysaker, P.H., 2014. Physical activity and psychiatric symptoms in adults with schizophrenia spectrum disorders. J. Nerv. Ment. Dis. 202 (12), 845-852.

Soundy, A., Roskell, C., Stubbs, B., Vancampfort, D., 2014. Selection, use and psychometric properties of physical activity measures to assess individuals with severe mental illness: a narrative synthesis. Arch. Psychiatr. Nurs. 28 (2), 135-151.

Stubbs, B., Ku, P.W., Chung, M.S., Chen, L.J., 2016b. Relationship Between Objectively Measured Sedentary Behavior and Cognitive Performance in Patients With Schizophrenia Vs Controls. Schizophr. Bull. http://dx.doi.org/10.1093/schbul/ sbw126.

Stubbs, B., Williams, J., Gaughran, F., Craig, T., 2016d. How sedentary are people with psychosis? A systematic review and meta-analysis. Schizophr. Res. 171 (1-3), 103-109.

Stubbs, B., Vancampfort, D., Manty, M., Svard, A., Rahkonen, O., Lahti, J., 2016c. Bidirectional longitudinal relationship between leisure-time physical activity and psychotropic medication usage: a register linked follow-up study. Psychiatry Res. 247, 208-213.

Stubbs, B., Firth, J., Berry, A., Schuch, F.B., Rosenbaum, S., Gaughran, F., Veronesse, N., Williams, J., Craig, T., Yung, A.R., Vancampfort, D., 2016a. How much physical activity do people with schizophrenia engage in? A systematic review, comparative meta-analysis and meta-regression. Schizophr. Res. 176 (2-3), 431-440.

Troiano, R.P., Berrigan, D., Dodd, K.W., Masse, L.C., Tilert, T., McDowell, M., 2008. Physical activity in the United States measured by accelerometer. Med. Sci. Sports Exerc. 40 (1), 181-188.

Trost, S.G., Loprinzi, P.D., Moore, R., Pfeiffer, K.A., 2011. Comparison of accelerometer cut points for predicting activity intensity in youth. Med. Sci. Sports Exerc. 43 (7), 1360-1368.

Ussher, M., Stanbury, L., Cheeseman, V., Faulkner, G., 2007. Physical activity preferences and perceived barriers to activity among persons with severe mental illness in the United Kingdom. Psychiatr. Serv. 58 (3), 405-408.

Vancampfort, D., Probst, M., Scheewe, T., De Herdt, A., Sweers, K., Knapen, J., van Winkel, R., De Hert, M., 2013. Relationships between physical fitness, physical activity, smoking and metabolic and mental health parameters in people with schizophrenia. Psychiatry Res. 207 (1-2), 25-32.

Vancampfort, D., Stubbs, B., Mitchell, A.J., De Hert, M., Wampers, M., Ward, P.B. Rosenbaum, S., Correll, C.U., 2015. Risk of metabolic syndrome and its component in people with schizophrenia and related psychotic disorders, bipolar disorder and major depressive disorder: a systematic review and meta-analysis. World Psychiatry 14 (3), 339-347. 
Vancampfort, D., Correll, C.U., Galling, B., Probst, M., De Hert, M., Ward, P.B., Rosenbaum, S., Gaughran, F., Lally, J., Stubbs, B., 2016. Diabetes mellitus in people with schizophrenia, bipolar disorder and major depressive disorder: a systematic review and large scale meta-analysis. World Psychiatry 15 (2), 166-174.

Walker, E.R., McGee, R.E., Druss, B.G., 2015. Mortality in mental disorders and global disease burden implications: a systematic review and meta-analysis. JAMA Psychiatry 72 (4), 334-341.

Wright, D.B., London, K., Field, A.P., 2011. Using bootstrap estimation and the plug-in principle for clinical psychology data. J. Exp. Psychopathology 2, 252-270. 